\title{
BMJ Open Impact of school closures on the health and well-being of primary school children in Wales UK: a routine data linkage study using the HAPPEN Survey (2018-2020)
}

\author{
Michaela James (D) , ${ }^{1}$ Emily Marchant, ${ }^{1}$ Margaret Anne Defeyter (D) , ${ }^{2}$ \\ Jayne Woodside, ${ }^{3}$ Sinead Brophy (D) ${ }^{1}$
}

To cite: James M, Marchant E, Defeyter MA, et al. Impact of school closures on the health and well-being of primary school children in Wales UK: a routine data linkage study using the HAPPEN Survey (2018-2020). BMJ Open 2021;11:e051574. doi:10.1136/ bmjopen-2021-051574

- Prepublication history and additional supplemental materia for this paper are available online. To view these files, please visit the journal online (http://dx.doi.org/10.1136/ bmjopen-2021-051574).

Received 23 March 2021 Accepted 01 September 2021

Check for updates

(c) Author(s) (or their employer(s)) 2021. Re-use permitted under CC BY-NC. No commercial re-use. See rights and permissions. Published by BMJ.

${ }^{1}$ Medical School, Swansea University, Swansea, UK ${ }^{2}$ Department of Psychology, Northumbria University, Newcastle upon Tyne, UK

${ }^{3}$ Centre for Public Health, Queen's University Belfast, Belfast, UK

Correspondence to Dr Michaela James; m.l.james@swansea.ac.uk

\section{ABSTRACT}

Objectives This study aimed to explore the relationship between initial school closures and children's health by comparing health and well-being outcomes collected during school closures (April-June 2020) via HAPPEN (the Health and Attainment of Pupils in a Primary Education Network) with data from the same period in 2019 and 2018 via the HAPPEN Survey.

Setting The study was conducted online with 161 primary schools across Wales involved in the 'HAPPEN At Home' Survey. Participants Data were collected via the 'HAPPEN At Home' Survey capturing the typical health behaviours of children aged 8-11 years from 1333 participants across Wales. These data were compared with data in 2018 and 2019 also collected between April and June, from HAPPEN (2019 $(n=1150)$ and $2018(n=475))$.

Primary and secondary outcome measures Primary outcomes included validated measures of physical activity, screen time, diet and dental health, as well as well-being, competency and autonomy. Free school meal (FSM) status was used as a proxy for socioeconomic deprivation. Analyses were repeated stratifying by FSM. Results Comparing responses between April-June in 2020 ( $n=1068), 2019(n=1150)$ and $2018(n=475)$, there were improvements in physical activity levels, sleep time, happiness and general well-being for children during school closures compared with previous years. However, children on FSM ate fewer fruits and vegetables (21\% less at five or more portions of fruits and vegetables (95\% Cl: $5.7 \%$ to $37 \%)$ ) and had lower self-assessed school competence compared with 2019. Compared with those not on FSM, they also spent less time doing physical activity (13.03\%, 95\% Cl: $3.3 \%$ to $21.7 \%)$ and consumed more takeaways ( $16.3 \%, 95 \% \mathrm{Cl}$ : $2 \%$ to $30 \%)$ during school closures.

Conclusions This study suggests that schools are important in reducing inequalities in physical health. The physical health (eg, physical activity and diet) of children eligible for FSM may be affected by prolonged school closures.

\section{INTRODUCTION}

In early March 2020, the WHO declared COVID-19 tobeaglobal pandemic. ${ }^{12}$ Toreduce the risk of person-to-person transmission, a

\section{Strengths and limitations of this study}

- This study provides a novel exploration of any differences in the health and well-being of children prior to and during the COVID-19 school closures between March and June 2020 using linked data.

- This is a pan-Wales study which recruited 1068 participants across Wales contributing to a significant gap in knowledge around the association of school closures with health and well-being.

- The exploration uses longitudinal self-report data from children linked with free school meal status as a proxy of deprivation.

- Although the 'HAPPEN At Home' Survey was made available to all children aged 8-11 years across Wales, the findings of this paper only present those who participated in the survey and a subsample who consented to data linkage.

wide range of public health measures were implemented by governments worldwide. These included the closure of educational settings in order to reduce the number of social contacts between pupils. ${ }^{34}$ By April 2020, the UNESCO estimated that 138 countries had implemented national school closures, impacting around $80 \%$ of children worldwide. ${ }^{4}$ In Wales, schools were required to close for statutory provision of education at the latest on 20 March $2020 .^{5}$

There is an ongoing debate regarding the effectiveness of school closures on transmission rates ${ }^{467}$ but the fact schools were closed for a long period of time could have had a negative association on pupil's mental and physical health. ${ }^{4689}$ For example, a study from England suggests $53.3 \%$ of girls and $44 \%$ of boys aged 13-18 years reported having anxiety and trauma above normative levels during lockdown-enforced school closures, ${ }^{10}$ 
while those aged 10-17 years reported lower life satisfaction in $18 \%$ of participants with $26.9 \%$ reported clinically low well-being scores. ${ }^{11}$ In terms of physical health, school closures may have reduced opportunities for physical activity, extracurricular activities, school meals and social interaction. ${ }^{12-15}$ Research shows that when children are out of school (eg, weekends and holidays), they are less physically active, and have longer screen time, irregular sleep patterns, less favourable diets, weight gain and a loss of cardiorespiratory fitness. ${ }^{6}{ }^{16}$ This is noted to be particularly detrimental for those from more deprived backgrounds. ${ }^{4} 1315$

A report by the Royal Society's Data Evaluation and Learning for Viral Epidemics group highlighted concerns regarding the increased inequalities in children's physical and mental health as a result of school closures. ${ }^{17}$ For example, pre-existing inequalities such as food poverty are likely to be exacerbated through reduced access to free school meals (FSMs). ${ }^{18}$ Thus, there is a real possibility that, in addition to a widening of the educational attainment gap which has been noted by research to be a learning loss of around 3 percentile points, or one-fifth of a school year, ${ }^{19}$ school closures are also likely to result in widening inequalities in children's physical health, mental well-being and health-related behaviours. While school closures were the primary change in children's lives, this, coupled with other restrictions such as social distancing, have been noted to result in feelings of isolation, stress, anxiety and unhappiness ${ }^{20}$ particularly as support networks (eg, friends, sports clubs) were unable to operate. ${ }^{21}$

This study aims to: (1) compare children's health and well-being during school closures in 2020 with the same period in 2019 and 2018; and (2) stratify the before and during period of school closures by socioeconomic deprivation (as measured by FSM eligibility). This study was a rapid response to the initial announcement of school closures in Wales which occurred 9 days after the WHO declared a global pandemic.

\section{METHODS}

\section{Study design}

HAPPEN (Health and Attainment of Pupils in a Primary Education Network) Wales was established at Swansea University in 2015 following research with head teachers who advocated for collaboration and a joined-up approach to prioritising health and well-being within the school setting. ${ }^{22}$ The network involves children aged 8-11 years completing the HAPPEN Survey, an online selfreport questionnaire that was developed and designed with children. The survey captures a range of information on health and well-being including nutrition, physical activity, sleep, well-being and concentration. ${ }^{23}$ Prior to school closures, children completed the survey within the school setting during curriculum time. A data collection and feedback system has been achieved by sharing group-level results to schools as a school report tailored to the curriculum. Annual reports are also shared with key stakeholders in health and education.

In light of the COVID-19 pandemic, HAPPEN aimed to understand how school closures were affecting the health and well-being of children in Wales. Therefore, the original HAPPEN Survey was adapted to the 'HAPPEN At Home' Survey to capture changes in health behaviours due to school closures and provide schools the opportunity to gain a better understanding of pupil's health and well-being. This enabled schools to plan for and address any concerns they identified within their 'HAPPEN At Home' report during the return to school.

\section{Participants}

Recruitment of participants and data collection were delivered online due to COVID-19 restrictions. Preexisting HAPPEN schools were emailed initially inviting them to participate in the 'HAPPEN At Home' Survey. Next, the survey was then opened wider and all primary schools in Wales were contacted through a number of methods including direct email, a social media campaign (paid advertisement on Facebook and Twitter) and promotion from key stakeholders (eg, regional education consortia). Schools were invited to share details of the survey (including study aims and a parent information sheet) among parents/guardians so that children could complete the survey at home at a convenient time. Communication between schools and parents/ guardians was achieved through existing channels such as text messages, newsletters and social media. This gave parents the opportunity to opt their child out from the survey. Child consent was also obtained at the start of the survey. This is the same sampling method as the 2019 data; however, 2018 data were collected in South Wales as the network was not pan-Wales in 2018. This opt-out method of recruiting participants aimed to ensure that a representative sample was recruited which could reflect all children in Wales.

\section{Patient and public involvement}

The research question was developed as a result of national school closures due to COVID-19 across the UK. The HAPPEN Survey was rapidly adapted to the 'HAPPEN At Home' Survey to address a significant gap regarding child-reported behaviours during school closures. The survey development involved input from key stakeholders including regional education consortia and primary school staff to ensure applicability of findings. The adapted 'HAPPEN At Home' Survey aimed to capture child-reported health and well-being during school closures to support schools in tailor health and well-being plans to suit the needs of their learners. Findings from the study will be reported back to schools via a report and social media dissemination.

\section{Data collection}

Primary data were collected via the 'HAPPEN At Home' Survey between April and June 2020. The survey captured 
the typical health behaviours of children aged 8-11 years. Items included validated measures of physical activity, screen time, diet and dental health, ${ }^{24}$ as well as wellbeing, competency and autonomy. Items included in the analyses are presented as online supplemental information 1. The full versions of the 'HAPPEN At Home' and original HAPPEN Survey can be viewed in the online supplemental information 2,3 respectively. The primary difference between the original survey and the 'at home' version was those questions relating to the school day specifically were removed during school closures.

The survey was conducted online and could be completed by children at home or in school (key worker or vulnerable children) via mobile phone, tablet and computer. The process of data coding involved two researchers. The first researcher downloaded the raw data, cleaned the data, checked for duplicates, generated a unique participant ID number and removed identifiable information. This process protects participants' anonymity by ensuring that the second researcher generating the report and conducting the analysis could not identify individuals. Raw data were coded using STATA (V.16) to produce a dataset for the purpose of analyses.

FSM status was used as a proxy for deprivation ${ }^{25}$ and was obtained via the Secure Anonymised Information Linkage (SAIL) Databank. ${ }^{26}$ To link the data, the demographic data are separated from the responses and sent to a trusted third party, The National Health Service (NHS) Wales Informatics Service, and the response data go to SAIL using a secure file upload. A unique Anonymous Linking Field is assigned to the person-based record before it is joined to clinical data via a system linking field.

\section{Analysis}

Primary analysis looked at whole group mean comparison of all children from 2018 and 2019 (preschool closures) to 2020 (school closures). Secondary analysis included the subset of children from 2019 to 2020 stratified by FSM.
The 2018 data were used to account for annual trends prior to lockdown. Two sample t-tests with equal variance using groups (years) were used to determine whether there was any significant difference between means for tables 1-3. This was carried out in STATA (V.16).

For the analysis, continuous data were dichotomised to bring in line with government guidelines, for example, physical activity and diet and dental health responses were coded as 1 if participants responded with being active for 7 days and 0 if less. Diet and dental health were coded as 1 if participants reported eating over five portions of fruits and vegetables and 1 if they reported brushing their teeth more than twice a day. Well-being question responses (including school) were coded as 1 if participants reported a score $\geq 8$ and a 1 if less than 7 . Mental health questions were coded as 1 if continuous scores equated to clinical emotional or behaviour difficulties. ${ }^{27}$ This coding then gave a percentage of participants meeting government guidelines for health behaviours in this age group. Online supplemental information 1provides further information on the variables used in the analysis.

For this paper, school closure was categorised as the period between 20 March 2020, the date in which the Minister for Education in Wales set for the closure of statutory education provision and 29 June 2020, the date in which schools returned for a phased approach in Wales. The 'HAPPEN At Home' Survey was launched on 23 April 2020 and closed on 26 June 2020. Analysis was carried out in November 2020 following data cleaning and SAIL linkage. This involved comparison of means to demonstrate any differences between time points. Presentation of the outcomes gives the CI of the difference between groups. The REporting of studies Conducted using Observational Routinely-collected Data (RECORD) statement has been used to underpin the reporting of these data.

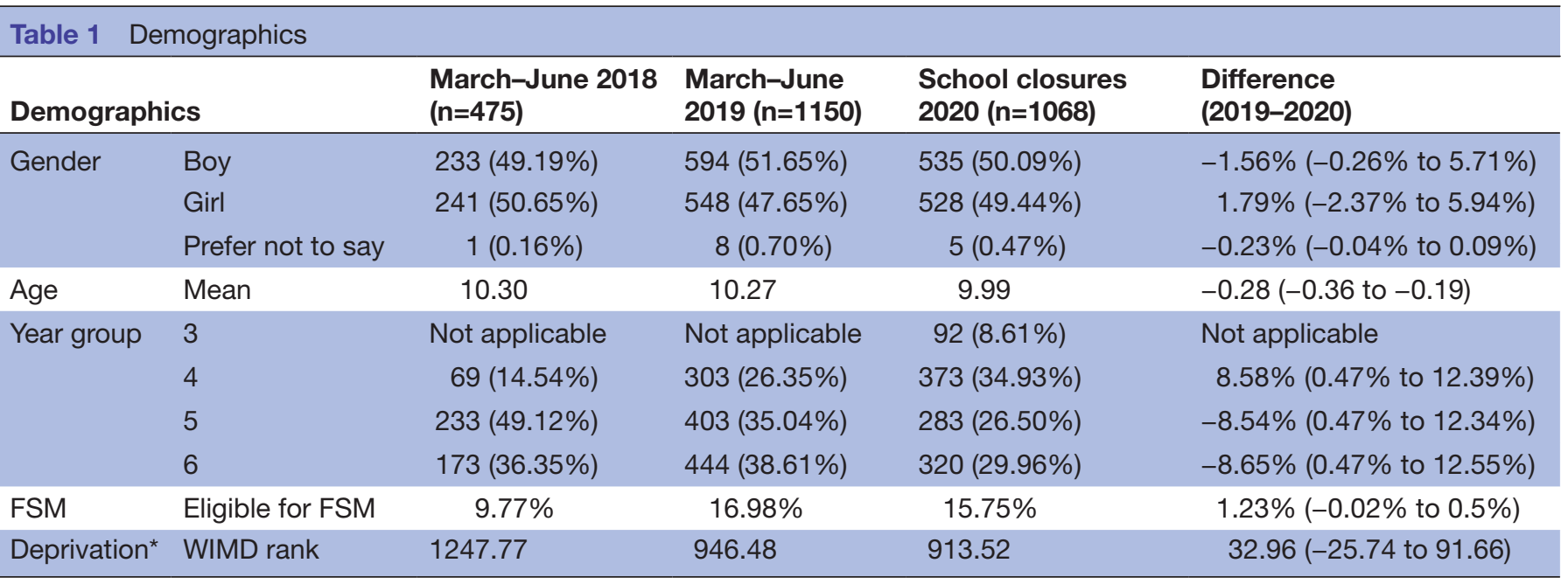

*As measured by the WIMD (WIMD is the official measure of relative deprivation in Wales where $1=$ most deprived and $1909=$ least deprived). ${ }^{42}$ FSM, free school meal; WIMD, Welsh Index of Multiple Deprivation. 
Table 2 Differences between those who took part in the HAH Survey and previous HAPPEN responses (group comparison between 2018, 2019 and 2020)

\begin{tabular}{|c|c|c|c|c|c|c|}
\hline & H/WB indicator & $\begin{array}{l}\text { March- } \\
\text { June 2018 } \\
(n=475)\end{array}$ & $\begin{array}{l}\text { March- } \\
\text { June 2019 } \\
(n=1150)\end{array}$ & $\begin{array}{l}\text { School } \\
\text { closures } \\
(n=1068)\end{array}$ & Difference (2018-2019) & $\begin{array}{l}\text { Difference (2019-school } \\
\text { closures) }\end{array}$ \\
\hline \multirow{7}{*}{$\begin{array}{l}\text { Physical } \\
\text { activity } \\
\text { and } \\
\text { screen } \\
\text { time }\end{array}$} & Activity & $21.57 \%$ & $22.78 \%$ & $27.32 \%$ & $1.21 \%(-3.50 \%$ to $5.93 \%)$ & $4.54 \%(0.93 \%$ to $8.14 \%)$ \\
\hline & Screen time & $27.94 \%$ & $33.22 \%$ & $56.61 \%$ & $5.28 \%(0.01 \%$ to $10.53 \%)$ & $23.39 \%$ (19.37\% to $27.43 \%)$ \\
\hline & Sleep & $84.31 \%$ & $80.43 \%$ & $90.82 \%$ & $-3.88 \%(-8.27 \%$ to $0.51 \%)$ & $10.39 \%(7.48 \%$ to $13.29 \%)$ \\
\hline & Tired & $14.22 \%$ & $15.39 \%$ & $8.45 \%$ & $1.17 \%(-2.87 \%$ to $5.22 \%)$ & $-6.94 \%(-9.64 \%$ to $-4.23 \%)$ \\
\hline & General competency & $88.35 \%$ & $84.26 \%$ & $90.82 \%$ & $-4.09 \%(-7.86 \%$ to $-0.30 \%)$ & $6.56 \%(3.81 \%$ to $9.31 \%)$ \\
\hline & Walk to park* & $\begin{array}{l}\text { Not } \\
\text { applicable }\end{array}$ & $88.81 \%$ & $94.37 \%$ & NA & $5.56 \%(3.24 \%$ to $7.87 \%)$ \\
\hline & Safe in area & $77.21 \%$ & $69.65 \%$ & $75.44 \%$ & $-7.56 \%(-12.63 \%$ to $-2.46 \%)$ & $5.79 \%(2.07 \%$ to $9.51 \%)$ \\
\hline \multirow{3}{*}{$\begin{array}{l}\text { Diet and } \\
\text { dental } \\
\text { health }\end{array}$} & Toothbrushing & $83.82 \%$ & $78.87 \%$ & $63.95 \%$ & $-4.95 \%(-0.45 \%$ to $-9.45 \%)$ & $-14.92 \%(-18.62 \%$ to $-11.21 \%)$ \\
\hline & Takeaway & $45.10 \%$ & $54.09 \%$ & $33.80 \%$ & $8.99 \%(3.35 \%$ to $14.62 \%)$ & $-20.29 \%(-24.34 \%$ to $-16.22 \%)$ \\
\hline & Fruit/vegetable & $83.09 \%$ & $71.30 \%$ & $69.94 \%$ & $-11.79 \%(-16.68 \%$ to $-6.88 \%)$ & $-1.36 \%(-0.5 .15 \%$ to $2.43 \%)$ \\
\hline \multirow{6}{*}{$\begin{array}{l}\text { Well- } \\
\text { being }\end{array}$} & Health score & $77.54 \%$ & $69.22 \%$ & $79.11 \%$ & $-8.32 \%(-13.14 \%$ to $-3.50 \%)$ & $9.89 \%(6.26 \%$ to $13.53 \%)$ \\
\hline & Family score & $90.04 \%$ & $88.09 \%$ & $94.47 \%$ & $-1.95 \%(-5.35 \%$ to $1.44 \%)$ & $6.38 \%(4.03 \%$ to $8.74 \%)$ \\
\hline & Friends score & $86.86 \%$ & $81.82 \%$ & $81.83 \%$ & $-5.04 \%(-9.03 \%$ to $-1.04 \%)$ & $0.01 \%(-3.20 \%$ to $3.22 \%)$ \\
\hline & Appearance score & $69.07 \%$ & $58.52 \%$ & $75.18 \%$ & $-10.55 \%(-15.73 \%$ to $-5.35 \%)$ & $16.66 \%$ (12.79\% to $20.53 \%)$ \\
\hline & Life score & $81.99 \%$ & $74.43 \%$ & $87.07 \%$ & $-7.56 \%(-12.08 \%$ to $-3.03 \%)$ & $12.64 \%(9.38 \%$ to $15.90 \%)$ \\
\hline & Autonomy & $88.35 \%$ & $89.22 \%$ & $85.11 \%$ & $0.87 \%(-2.49 \%$ to $4.23 \%)$ & $-4.11 \%(-6.8 \%$ to $-1.32 \%)$ \\
\hline $\begin{array}{l}\text { Mental } \\
\text { health }\end{array}$ & Emotional difficulties & $14.19 \%$ & $20.96 \%$ & $12.17 \%$ & $6.77 \%(2.56 \%$ to $10.95 \%)$ & $-8.79 \%(-11.87 \%$ to $-5.69 \%)$ \\
\hline
\end{tabular}

Bold denotes significance $(\mathrm{p}=0.05)$.

${ }^{*}$ Question not included in HAPPEN in 2018 survey.

HAH, HAPPEN At Home; HAPPEN, Health and Attainment of Pupils in a Primary Education Network; H/WB, health/well-being.

\section{RESULTS}

The 'HAPPEN At Home' Survey had 1333 responses, from 161 primary schools across Wales. Following the exclusion process presented in figure 1 (no consent for linkage, missing FSM data), the final linked data ('HAPPEN At Home' responses and FSM status) for subsequent analysis included 574 participants. Data were stratified by FSM status and compared with 2019 from the same time period (March-June 2019). A breakdown of demographics by FSM status and time period is presented in table 1. It is worth highlighting that there are no significant differences between 2019 and 2020 demographics. However, the 2019 cohort was significantly less deprived than 2018 (FSM eligibility: $-7.2 \%, 95 \%$ CI: $-11.39 \%$ to $-3.01 \%$, Welsh Index of Multiple Deprivation: 301.28, 95\% CI: 227.61 to 374.96$)$.
Differences in health outcomes before (2018-2019) and during school closures (2020)

During school closures, there was a significant improvement in physical activity (see table 2) $(4.5 \%$ increase in number achieving $60 \mathrm{~min}$ of physical activity a day, 95\% CI: $0.95 \%$ to $8.14 \%)$ and in sleep (10.39\% more having the recommended 9-hour sleep, $95 \%$ CI: $7.48 \%$ to $13.29 \%)$. Children also report increases in screen time (23.39\%, 95\% CI: $19.37 \%$ to $27.43 \%$ ) and feeling less tired $(-6.94 \%, 95 \%$ CI: $9.64 \%$ to $-4.23 \%)$. There were no significant differences in these variables between 2018 and 2019 suggesting that these findings are associated with lockdown restrictions and school closures as opposed to time trends. Perceptions of general competency and feeling safe in your area (online supplemental information 1) also increased during school closures.

Regarding dietary and dental health behaviours, the amount of daily toothbrushing decreases annually (table 2) but this is more pronounced between 2019 and $2020(-14.92 \%, 95 \%$ CI: $-18.62 \%$ to $-11.21 \%)$. 


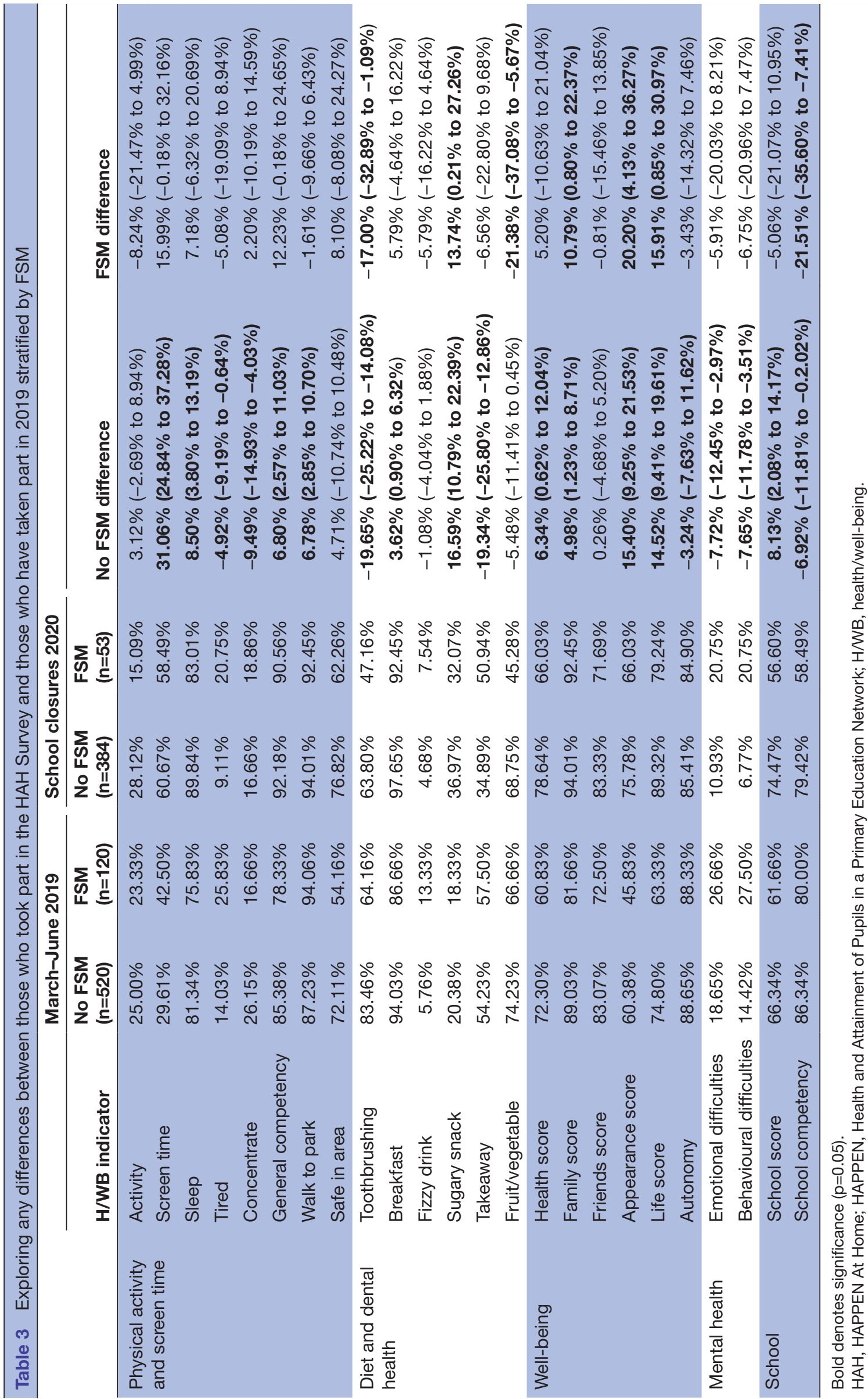




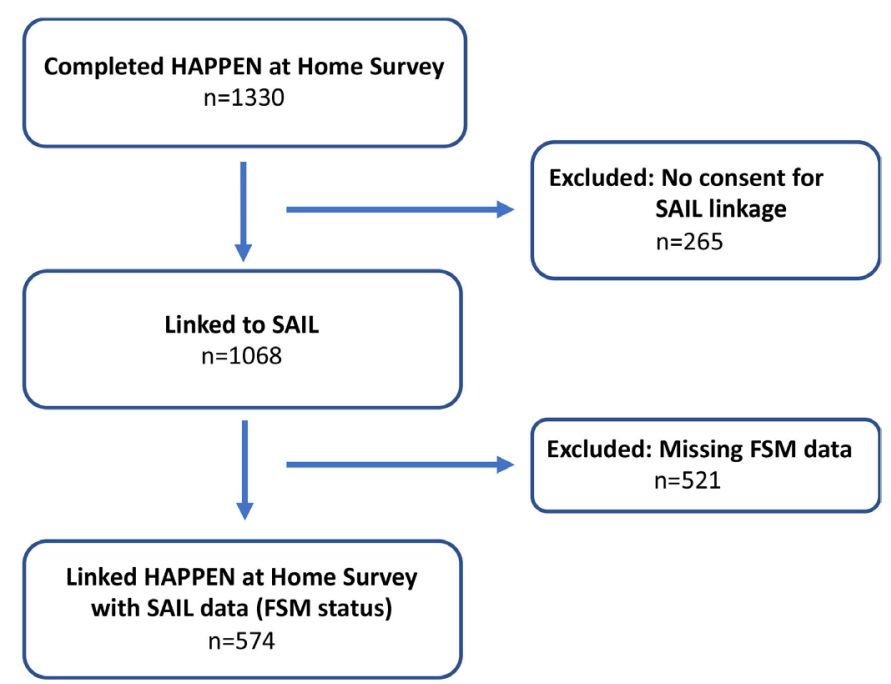

Figure 1 Flow of HAPPEN Study (exclusion process and data linkage). FSM, free school meal; HAPPEN, Health and Attainment of Pupils in a Primary Education Network; SAIL, Secure Anonymised Information Linkage.

Interestingly, the number of takeaways consumed per week has decreased during 2020 (-20.29\%, 95\% CI: $-24.34 \%$ to $-16.33 \%$ ), while sugary snack consumption has increased (15.03\%, 95\% CI: $11.31 \%$ to $18.74 \%)$. However, there appears to be an annual trend in sugary snack consumption when compared with 2019 and 2018 data. A higher proportion of children report eating breakfast during school closures compared with previous years $(4.85 \%, 95 \%$ CI: $3.00 \%$ to $6.69 \%)$.

Between 2018 and 2019, well-being shows decreases in a number of areas including perceptions of health $(-8.32 \%, 95 \%$ CI: $-13.14 \%$ to $-3.50 \%)$, friends $(-5.04 \%$, $95 \%$ CI: $-9.03 \%$ to $-1.04 \%)$, appearance $(-10.55 \%$, $95 \%$ CI: $-15.73 \%$ to $-5.35 \%)$ and life $(-7.56 \%, 95 \%$ CI: $-12.08 \%$ to $-3.03 \%)$. However, during school closures, this trend reversed (table 2). Most notably, children reported being happier with their health $(9.89 \%, 95 \% \mathrm{CI}$ : $6.26 \%$ to $13.53 \%)$, appearance $(16.66 \%, 95 \%$ CI: $12.79 \%$ to $20.53 \%)$ and life $(12.64 \%, 95 \%$ CI: $9.38 \%$ to $15.90 \%)$. A similar trend is evident in terms of mental health (fewer emotional $(-8.79 \%(-11.87 \%$ to $-5.69 \%)$ and behavioural difficulties $(-5.89 \%(-8.58 \%$ to $-3.19 \%))$.

Despite being away from the school environment, children report feeling happier with school compared with $2019(4.23 \%(0.09 \%$ to $8.36 \%))$. Yet, their self-reported school competency was reduced during school closures $(-21.51 \%(-35.60 \%$ to $-7.41 \%))$. However, there is an annual decrease since 2018 suggesting a temporal trend in pupils' perception of school ability $(-6.92 \%(-11.81 \%$ to $-0.2 .02 \%)$ ).

Differences in health outcomes before (2018-2019) and during school closures (2020) stratified by deprivation (FSM eligibility)

Compared with non-FSM children (table 3), those eligible for FSM walked to the park less (compared with a $6.78 \%$ increase in non-FSM $(2.85 \%$ to $10.70 \%))$, their takeaway consumption showed less decline $(-6.54 \%$ compared with $-19.34 \%$ in non-FSM) but their fruit and vegetable consumption significantly declined $(-21.28 \%, 95 \%$ CI: $-37.08 \%$ to $-5.67 \%$ ). This decline was not seen in nonFSM children. The decline in perceptions of school competency from 2019 to 2020 was three times higher within the FSM group (-21.51\% ( $-35.60 \%$ to $-7.41 \%)$ ).

During school closures, there was a significant difference of reported daily physical activity between those on FSM and those not on FSM (13.03\% difference, 95\% CI: $3.3 \%$ to $21.66 \%$ ). Compared with non-FSM children, a lower proportion of FSM-eligible children reported to engage in at least 60 min of daily physical activity during school closures (non-FSM: 28.12\%; FSM: 15.09\%). Children not on FSM showed a significant increase in screen time $(31.06 \%(24.84 \%$ to $37.28 \%))$ and reported a lower ability to concentrate $(-9.49 \%(-14.93 \%$ to $-4.03 \%))$. However, there was an increase from 2019 to 2020 in family well-being scores for all children and especially among those eligible for FSM (non-FSM: 4.98\%; FSM: $10.79 \%)$. It is worth noting that the majority of differences, particularly improvements, in health behaviours were noted within the non-FSM group suggesting that findings for the overall group during school closures were driven by those who are not eligible for FSM.

\section{DISCUSSION}

This study aimed to capture the associations between the initial school closures between March and June 2020 and the health and well-being of children. Improvements during school closures for children included physical activity, sleep, well-being (family, health, life) and emotional and behavioural difficulties. However, it is likely that these improvements were predominantly because of participants who were not eligible for FSMs according to this study's findings, highlighting the health inequalities between less and more deprived that existed even prior to the pandemic and school closures. Primary school children report higher well-being especially family score, during lockdown. However, aspects which were detrimental during school closures included less toothbrushing for all children. FSM children reported a reduction in the time spent engaged in physical activity, significantly less fruit and vegetable consumption and lower self-assessed school competence than before school closures.

\section{Physical activity and screen time}

Overall, small improvements to time spent being physically active were seen during school closures. However, this increase is likely to be among non-FSM pupils. For those on FSM activity decreased, recent research around school staff perceptions of the return to school echoes this finding. Teachers perceived that their pupils had been less active during lockdown restrictions and observed on the phased return to school that some children had gained weight. ${ }^{28}$ Findings from the current study suggest 
this may be more pronounced for more deprived pupils. Those eligible for FSM did report feeling less safe in their areas which may be why they were less active. Evidence shows that physical activity is associated with the wider environment including the socioeconomic status of a neighbourhood which underpins the contextual effects of higher social disorder and lower perceived safety as the status lowers. ${ }^{29}$ However, those not eligible for FSM report feeling safer in their local areas. Therefore, this study suggests that the implications of being confined to your local area during periods of restricted movement alongside parents/caregivers may improve perceptions of safety for those less deprived. This, in turn, could mean they were happier to be active in their areas which would account for differences in physical activity by deprivation. Due to the lack of significant difference in deprivation levels between 2019 and 2020, it is likely that increased exposure to these environments would account for higher safety scores rather than a difference in cohort demographics.

Non-FSM children were more active. However, nonFSM children's screen time was significantly higher during school closures. Their reported daily screen time ( $>2$ hours) doubled compared with the previous year. This is comparative with similar research which also notes increases in screen time during the pandemic. ${ }^{30}$ It has been proposed that this could be because of loosening household rules around screen time usage to facilitate entertainment or social connection through computer games or social media. ${ }^{30}$ While deprivation is associated with higher screen time in adults, ${ }^{31}$ it is less clear what that means for children. This study suggests that less deprived children have higher screen time which is a contrast to adults. It may be that these children have more access to technology which enables screen time.

The HAPPEN Survey asks about screen time in reference to 'TV, video games and using the internet'. It is possible that children perceived using the internet as the delivery of education through online learning. Thus, children will have used screens (eg, laptops and tablets) to aid learning. Less deprived families may have better access to these resources and therefore, screen time may be higher in this group. This is supported by research from the Institute for Fiscal Studies ${ }^{32}$ where children from less deprived families were spending $30 \%$ more time engaging in home learning activities than those more deprived. This may also reflect why perceptions of school competency remain much higher in the less deprived group. This suggests that non-FSM children were more engaged with learning tasks and therefore had perceived higher competence and confidence with learning and development. This may contribute towards the estimated $46 \%$ increase in learning gap between disadvantaged children and their peers reported by teachers. ${ }^{33}$ With the relationship between education and health well documented, this has implications for children's future health and well-being outcomes. ${ }^{34}$ Further evidence of this is seen in feeling part of your school community which again is much higher in those not on FSM.

For those eligible for FSM, the amount of screen time may appear positive in comparison with non-FSM but could also highlight inequalities relating to digital poverty and contribute to gaps in learning progression. Previous HAPPEN research ${ }^{28}$ has highlighted the lack of access to digital equipment, sharing devices and a lack of digital competency in accessing home learning. This is worth noting as while less screen time could be perceived as a benefit to physical health in FSM children, during school closures it could also mean that learning gaps are being widened.

Children not on FSM report to not being able to concentrate as much compared with the previous year. The increased screen time may be due to increased online working for non-FSM pupils during school closures that may have been detrimental to concentration. More research into how screen time was consumed during school closures and the impact this has on health is required.

\section{Diet and dental health}

Toothbrushing was significantly lower in children compared with 2019 regardless of FSM status. This meant many children were brushing their teeth less than the recommended guidelines of twice per day. Research shows that lack of routine and structure puts children at risk of poorer dental hygiene ${ }^{35}$ which can have longterm effects. It is possible that school closures disrupted bedtime and wake time routines in which toothbrushing would usually take place, and therefore may account for the lower frequency of toothbrushing. In addition, the lack of access to school-based dental hygiene programmes such as 'Designed to Smile' ${ }^{36}$ may have a significant impact on toothbrushing behaviour. This coupled with observed increases in sugary snack consumption through school closures may have negative associations with dental hygiene.

Those on FSM saw the biggest effect on dietary behaviours during lockdown restrictions. Not only was takeaway consumption higher in this group, but FSM children also consumed fewer fruits and vegetables during this time. FSMs are a key public health policy to aid in reducing food insecurity and associated negative health and educational inequalities in the UK. It appears that those using FSM have been significantly affected by school closures in not being able to access regular meal provision in a school setting in Wales. Research shows that almost half of all children on FSM were unable to access them during school closures. ${ }^{37}$

Providing children with nutritional meals in school helps to narrow health inequalities and the educational attainment gap between the most and least deprived children. ${ }^{38}$ Findings from this study add further evidence to disparities among groups of children from different backgrounds. While the initial lockdown in March 2020 was temporary, the findings of the current study support 
the mounting evidence that prolonged lockdown periods will affect children's physical health. ${ }^{37}$

\section{Well-being and mental health}

Within this current study, improvements in family wellbeing were observed during school closures for both groups of children. This is likely due to an increased number of parents working from home or being furloughed, enabling some children to spend extra time that they otherwise would not have had with caregivers. School staff acknowledge this, they reported children having more opportunities for walking, exploring and spending time outside, with this contributing to strengthened family relationships. ${ }^{28}$

Happiness with life was also significantly higher generally and increased equally in both groups from 2019 data. It is important to note that deprived children still report feeling less happy in general compared with nonFSM children. The findings regarding physical activity may underpin this, with increased opportunities to play and be outdoors, for example, having more time during lockdown and feeling safer in their areas. Moreover, behavioural and emotional difficulties reported during school closures were significantly lower. In less deprived children, this number was almost half suggesting a more positive relationship in those not on FSM. Interestingly, previous research has found the opposite, with parents and teachers reporting increases in emotional and behavioural difficulties as well as low mood, anxiety and social disconnection. ${ }^{28}{ }^{40}$ It is possible these conflicting findings highlight the difference between child reported and adult external observations.

\section{Limitations}

Although the 'HAPPEN At Home' Survey was made available to all children aged 8-11 years across Wales, the findings of this paper only present those who participated in the survey and a subsample who consented to data linkage. As the survey took place at home due to school closures, those who participated will be from families who have internet access. The difference in inequalities is likely to be much higher among those who could not participate due to lack of access to the internet. This also means we cannot ensure a fully representative sample of children has been recruited across Wales. While the sampling strategy was the same for 2020 and 2019, 2018 data were sampled more purposefully from South Wales which may have an influence on findings from this year. Furthermore, a small subset of participants $(n=14)$ responded at two time points to the various HAPPEN Surveys. This sample was too small to analyse and therefore, it is not possible to identify the independence which is a limitation of this study.

There is evidence that FSM status is not a perfect measure of socioeconomic deprivation ${ }^{41}$ and there are also a number of other factors that contribute to the deprivation levels of a child. However, FSM status does come very close to identifying a group of children who may be at disadvantage due to their socioeconomic position. ${ }^{41}$ With this in mind, it is also possible that differences between the three groups are due to sample characteristics (eg, varying deprivation levels) in conjunction with school closures.

\section{Conclusion}

Overall, findings from this study show that, as a group, many things improved during the period of school closures for children including physical activity, sleep and general well-being. However, there are significant differences and inequalities when stratified by FSM. Improvements were mostly observed in non-FSM children. For children eligible for FSM, diet (eg, lower fruit and vegetable intake), physical activity and dental health were significantly affected. These findings are concerning as they illustrate the importance of the entire school day, including FSM provision, in attenuating physical health inequalities in children.

This paper shows the short-term associations of school closures on children's health and well-being and it is worth noting that the long-term impacts of further school closures and national lockdown may have more detrimental impacts on the health and well-being of children. This research highlights a number of concerns regarding wider physical health inequalities such as obesity. When schools reopen, this research suggests there will be a need to address wider physical health inequalities such as obesity, poor dental health, lack of vitamins and minerals and lower fitness in those from deprived backgrounds.

\section{Twitter Margaret Anne Defeyter @livinghealthy and Sinead Brophy @@SineadBr}

Acknowledgements The authors thank key stakeholders from regional consortia and schools for their participation in the development of the 'HAPPEN At Home' Survey.

Contributors MJ wrote the first draft of the paper and all authors provided critical input and revisions for all further drafts. MJ, EM and SB designed data collection and $\mathrm{MJ}$ and $\mathrm{SB}$ undertook data analysis. MJ, EM, SB, MAD and JW aided in interpretation of findings and supervision of study quality.

Funding This work was supported by the National Centre for Population Health and Wellbeing Research (NCPHWR) funded by Health and Care Research Wales and Welsh Government. No financial disclosures were reported by the authors of this paper. The collaborations of the authors were made possible by the GENIUS network. GENIUS is supported by the UK Prevention Research Partnership, an initiative funded by UK Research and Innovation Councils, the Department of Health and Social Care (England) and the UK devolved administrations, and leading health research charities.

Disclaimer The funders had no further involvement other than providing financial support.

Competing interests None declared.

Patient consent for publication Obtained.

Ethics approval The survey was granted ethical approval by Swansea University's Medical School on 15 April 2020 (reference: 2017-0033B).

Provenance and peer review Not commissioned; externally peer reviewed.

Data availability statement No data are available.

Supplemental material This content has been supplied by the author(s). It has not been vetted by BMJ Publishing Group Limited (BMJ) and may not have been peer-reviewed. Any opinions or recommendations discussed are solely those of the author(s) and are not endorsed by BMJ. BMJ disclaims all liability and responsibility arising from any reliance placed on the content. Where the content 
includes any translated material, BMJ does not warrant the accuracy and reliability of the translations (including but not limited to local regulations, clinical guidelines, terminology, drug names and drug dosages), and is not responsible for any error and/or omissions arising from translation and adaptation or otherwise.

Open access This is an open access article distributed in accordance with the Creative Commons Attribution Non Commercial (CC BY-NC 4.0) license, which permits others to distribute, remix, adapt, build upon this work non-commercially, and license their derivative works on different terms, provided the original work is properly cited, appropriate credit is given, any changes made indicated, and the use is non-commercial. See: http://creativecommons.org/licenses/by-nc/4.0/.

\section{ORCID iDs}

Michaela James http://orcid.org/0000-0001-7047-0049

Margaret Anne Defeyter http://orcid.org/0000-0003-2808-523X

Sinead Brophy http://orcid.org/0000-0001-7417-2858

\section{REFERENCES}

1 World Health Organisation. WHO announces COVID-19 outbreak a pandemic. Available: https://www.euro.who.int/en/health-topics/ health-emergencies/coronavirus-covid-19/news/news/2020/3/whoannounces-covid-19-outbreak-a-pandemic [Accessed 29 Apr 2021].

2 British Broadcasting Company (BBC). Coronavirus confirmed as pandemic by World Health Organization.

3 Viner RM, Russell SJ, Croker H, et al. School closure and management practices during coronavirus outbreaks including COVID-19: a rapid systematic review. Lancet Child Adolesc Health 2020;4:397-404.

4 Van Lancker W, Parolin Z. COVID-19, school closures, and child poverty: a social crisis in the making. Lancet Public Health 2020;5:e243-4.

5 Welsh Government, Statement from Minister for Education. Kirsty Williams on school closures in Wales.

6 Wang G, Zhang Y, Zhao J, et al. Mitigate the effects of home confinement on children during the COVID-19 outbreak. Lancet 2020;395:945-7.

7 Brooks SK, Smith LE, Webster RK, et al. The impact of unplanned school closure on children's social contact: rapid evidence review. Eurosurveillance 2020;25

8 Liu JJ, Bao Y, Huang X, et al. Mental health considerations for children quarantined because of COVID-19. Lancet Child Adolesc Health 2020;4:347-9.

9 Lyons RA, Jones $\mathrm{KH}$, John G. BMC medical informatics and The SAIL databank : linking multiple health and social care datasets 2009:8:1-8.

10 Levita L. Initial research findings on the impact of COVID-19 on the well-being of young people aged 13 to 24 in the UK. Psychol Res Consort 2021;53:6 http://dspace.ucuenca.edu.ec/bitstream/ 123456789/35612/1/Trabajo de Titulacion.pdf\%0Ahttps:// educacion.gob.ec/wp-content/uploads/downloads/2019/01/GUIAMETODOLOGICA-EF.pdf

11 The Children's Society. Life on hold 2020

12 World Health Organization (WHO). Considerations for school-related health measures in the context of COVID-19.

13 European Network of Ombudpersons for Children (ENOC) and United Nations International Children's Fund. Ombudspersons and commissioners for children's challenges and responses to Covid-19, 2020. Available: http://enoc.eu/wp-content/uploads/2020/06/ENOCUNICEFF-COVID-19-survey-updated-synthesis-report-FV.pdf

14 United Nations Educational Scientific and Cultural Organisation (UNESCO). Adverse consequences of school closures, 2020. Available: https://en.unesco.org/covid19/educationresponse/ consequences

15 European Centre for Disease Prevention and Control. COVID-19 in children and the role of school settings in COVID-19 transmission key messages, 2020.

16 Rundle AG, Park Y, Herbstman JB, et al. COVID-19-related school closings and risk of weight gain among children. Obesity 2020;28:1008-9.

17 The DELVE Initiative. Balancing the Risks of Pupils Returning to Schools. DELVE report No. 4. Available: https://rs-delve.github. io/reports/2020/07/24/balancing-the-risk-of-pupils-returning-toschools.html [Accessed 7 Jan 2021].
18 Mamot M, Allen J, Goldblatt P. Build back fairer: the COVID-19 Marmot review. The pandemic, socioeconomic and health inequalities in England. London Inst Heal Equity 2020.

19 Engzell P, Frey A, Verhagen MD. Learning loss due to school closures during the COVID-19 pandemic. Proc Natl Acad Sci U S A 2021;118 doi:10.1073/pnas.2022376118

20 Singh S, Roy D, Sinha K, et al. Impact of COVID-19 and lockdown on mental health of children and adolescents: a narrative review with recommendations. Psychiatry Res 2020;293:113429.

21 Day L, Percy-smith B, Rizzo S, et al. To lockdown and back: research report, 2020.

22 Todd C, Christian D, Davies H, et al. Headteachers' prior beliefs on child health and their engagement in school based health interventions: a qualitative study. BMC Res Notes 2015;8:1-10.

23 Todd C, Chistian D, Tyler R, et al. Developing happen (health and attainment of pupils involved in a primary education network): working in partnership to improve child health and education. Perspect Public Health 2016;136:115-6.

24 Everson B, Mackintosh KA, McNarry MA, et al. Can wearable cameras be used to validate school-aged children's lifestyle behaviours? Children 2019;6:20.

25 Ilie S, Sutherland A, Vignoles A. Revisiting free school meal eligibility as a proxy for pupil socio-economic deprivation. Br Educ Res J 2017;43:253-74.

26 Ford DV, Jones KH, Verplancke J-P, et al. The SAIL databank: building a national architecture for e-health research and evaluation. BMC Health Serv Res 2009;9:1-12.

27 Deighton J, Tymms P, Vostanis P, et al. The development of a school-based measure of child mental health. J Psychoeduc Assess 2013;31:247-57

28 Marchant E, Todd C, James M. Primary school staff reflections on school closures Due to COVID-19 and recommendations for the future : a national qualitative survey 2020.

29 Pabayo R, Belsky J, Gauvin L, et al. Do area characteristics predict change in moderate-to-vigorous physical activity from ages 11 to 15 years? Soc Sci Med 2011;72:430-8.

30 Fry C. Sleep deprived but socially connected: balancing the risks and benefits of adolescent screen time during COVID-19. J Child Media 2021;15:37-40.

31 Ogunleye AA, Voss C, Sandercock GR. Prevalence of high screen time in English youth: association with deprivation and physical activity. J Public Health 2012;34:46-53.

32 Andrew A, Cattan S, Dias MC. Learning during the lockdown: real-time data on children's experiences during home learning: IFS Briefing note BN288. Institute for Fiscal Studies.

33 Sharp C, Nelson J, Lucas M, et al. The challenges facing schools and pupils in September 2020. The National Foundation for Educational Research.

34 Feinstein L, Sabates R, Anderson TM. Measuring the effects of education on health and civic engagement. Proc Copenhagen Symp 2006:171-354 https://www.oecd.org/education/innovationeducation/37425753.pdf

35 Duijster D, Verrips GHW, van Loveren C. The role of family functioning in childhood dental caries. Community Dent Oral Epidemiol 2014;42:193-205.

36 NHS Wales. Designed to SMILE, 2020. Available: https://www. designedtosmile.org/welcome-croeso/welcome/ [Accessed 7 Jan 2021].

37 Parnham JC, Laverty AA, Majeed A, et al. Half of children entitled to free school meals did not have access to the scheme during COVID-19 lockdown in the UK. Public Health 2020;187:161-4.

38 Stewart $\mathrm{CH}$, Dundas R, Leyland $\mathrm{AH}$. The Scottish school leavers cohort: linkage of education data to routinely collected records for mortality, hospital discharge and offspring birth characteristics. BMJ Open 2017;7:e015027.

39 et alShaw B, Baars S, Menzies L. Low income pupils' progress at secondary school, 2017. Available: https://www.gov.uk/government/ publications/low-income-pupils-progress-at-secondary-school

40 Pearcey S, Shum A, Waite P, et al. Changes in children and young people's emotional and behavioural difficulties through lockdown: The Co-SPACE Study. 2020:1-28.

41 Taylor C. The reliability of free school meal eligibility as a measure of socio-economic disadvantage: evidence from the millennium cohort study in Wales. Br J Educ Stud 2018;66:29-51.

42 Statistics for Wales. Welsh index of multiple deprivation, 2011. Available: www.wales.gov.uk/statistics 